\title{
An Investigation of the Failure Mechanisms of Lead Anodes in Copper Electrowinning Cells
}

\author{
A. Elrefaey, Y. Gu, J.D. James, C. Kneen, I. Crabbe, J. Sienz
}

\begin{abstract}
Lead alloys are used as permanent anodes for electrowinning of base metals such as copper. The corrosion of anodes is costly because of their relatively short lifetime, material cost, and their impact on cathodic deposit quality. Failure of anodes sometimes occurs before the predicted lifetime, having a negative impact on the efficiency and economics of the electrowinning process.

This study investigates some recently failed lead alloy anodes. These failures occurred after a short period of service in a commercially operating electrowinning tank house. The samples were metallographically investigated with the help of an optical, three-dimensional microscope and a scanning electron microscope (SEM) equipped with Energy-Dispersive X-ray Spectroscopy (EDS) analysis. It is suggested that the reasons for failure are improper operational issues in the tank house, especially the level of manganese content in the electrolyte, which leads to unexpected corrosion.
\end{abstract}

Key words: Lead anodes, Manganese, Electrowinning, copper, microstructure

\section{Introduction}

Approximately $20 \%$ of the world's copper is produced by electrowinning processes [1]. This is carried out in large commercial "tank houses" which contain several hundred electrodes and utilize a mixture of copper sulphate and sulphuric acid as the electrolyte. Copper is precipitated at the cathodes and the corresponding reaction at the anodes is one of oxygen evolution, so that the overall equation [2] is:

$$
\mathrm{CuSO}_{4}+2 e^{-}+\mathrm{H}_{2} \mathrm{O} \rightarrow \mathrm{Cu}+\mathrm{H}_{2} \mathrm{SO}_{4}+\frac{1}{2} \mathrm{O}_{2}
$$

The characteristic features of lead such as corrosion resistance and electrical conductivity as well as the economical price makes it the best choice as the anode material. Lead forms a continuities protective layer of $\mathrm{PbO}_{2}$ which is conductive for the circuit and prohibits the corrosion attack of the anode [1-6].

Traditionally, electrowinning of copper relied on lead and lead alloys as the anode material in the tank houses. Over the last few decades there has been a trend to replace lead-antimony alloys with anodes based on lead-calcium-tin. Alloying lead with calcium is beneficial to increase the mechanical strength of the anode while tin improves its corrosion resistance, prevents the formation of a non-conducting $\mathrm{PbSO}_{4}$ layer (by providing higher conductivity paths of $\mathrm{SnO}_{2}$ ), and improves the oxygen evolution [2]. The overall advantages of this alloy are increased life time and efficiency of the anode.

The properties of lead dioxide which formed at the surface of lead anode is of great importance to the efficiency of lead based anodes $[2,7,8]$. There are two layers at the anode surface. The first layer is close to the anode itself, separates it from the electrolyte, and called $\alpha$-phase. The second layer is located in between the protective $\alpha-\mathrm{PbO}_{2}$ phase and the electrolyte and called $\beta$-phase. Fig. 1 shows a schematic representation of the lead anode and the attached layers [2]. The structure of $\alpha-\mathrm{PbO}_{2}$ was reported to be more compact, adherent and dense than the $\beta$-phase $[2,7,9]$. Therefore, the increase of thickness of lead dioxide layers led to an increase in corrosion resistance of the anode. When the layer become loose and less adherent, corrosion attack proceeds and layers of anode dissolve regularly. 
In spite of the low cost of lead anodes, the overall cost of corrosion of these anodes is considerable owing to the numerous of anodes used in a plant. Therefore, corrosion problems associated with lead anodes in commercial copper electrowinning plants is significant to the manufacturer. Regular maintenance of the anode and employing the optimum operating condition of the tank house helps to increase the life time of the anodes. Normally, the anodes may be used for 4 to 6 years before replacing since it is corroded by circa $0.5 \mathrm{~mm} /$ year [10-11].

Recently, the authors examined two lead alloy anodes from different manufacturers that failed under unusually short periods of service. The aim was to investigate the two anodes and detect the reason of failure after the short time service.

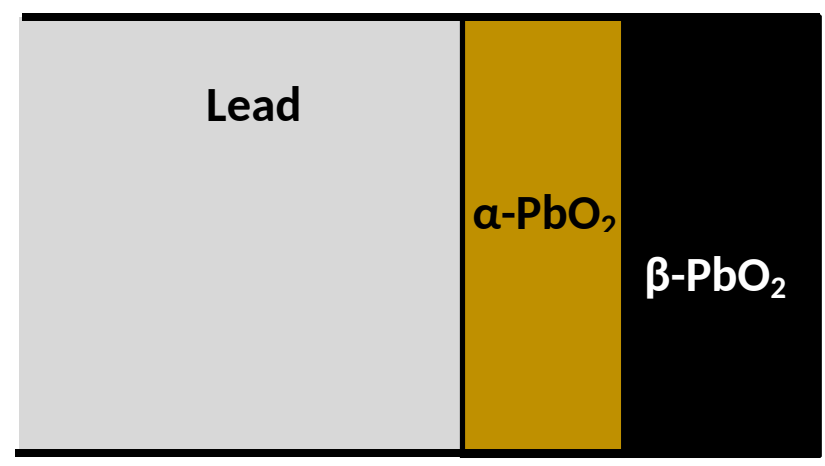

Fig. 1 Lead anode corrosion on sulphuric acid [2]

\section{Experimental}

Two failed anode samples (manufacturer A \& manufacturer B) were received as shown in Fig. 2. Both samples were sheets about $150 \times 100 \mathrm{~mm}, 6 \mathrm{~mm}$ thick, with general corrosion surfaces. The anode from manufacturer B additionally showed pitting corrosion from both sides.

The macrostructures of the samples' surfaces were investigated by optical and 3-D microscopes (KEYENCE VHX-1000) to analyse the surface features especially the dimensions of the corrosion pits. Later on, small sections from the surface and cross section were taken to carry out investigation by SEM and EDS.

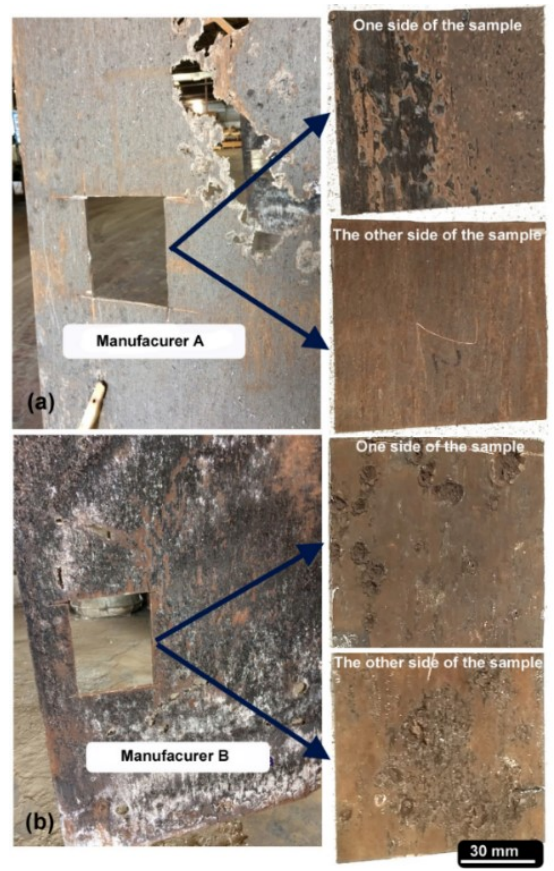

Fig. 2 Samples received for investigation; (a) anode from manufacturer A, (b) anode from manufacturer B 
During preparation for metallography, alumina abrasive papers were used. These were preferred to silicon carbide papers because lead is very soft and distortion of the microstructure can easily occur. Excessive heat should also be avoided during preparation to avoid the recrystallization of the microstructure at the surface. Primarily because lead and lead alloys smear and blacken so easily, etching-polishing alternated with examination under the microscope is required. Several cycles of polishing, etching, cleaning and examination are necessary. Etching was carried out using $30 \mathrm{ml}$ acetic acid $+40 \mathrm{ml}$ nitric acid $+160 \mathrm{ml}$ distilled water at $40^{\circ} \mathrm{C}$ for several seconds.

Fig. 3 represents the obtained base metal microstructure feature of the two different manufacturer's anodes. In the rolled lead alloys microstructure, the grains are fully thinned and stretched in the rolling direction. Additionally, it is also noted that the grains are not ordered and possess sharp edges, particularly in the anode B.
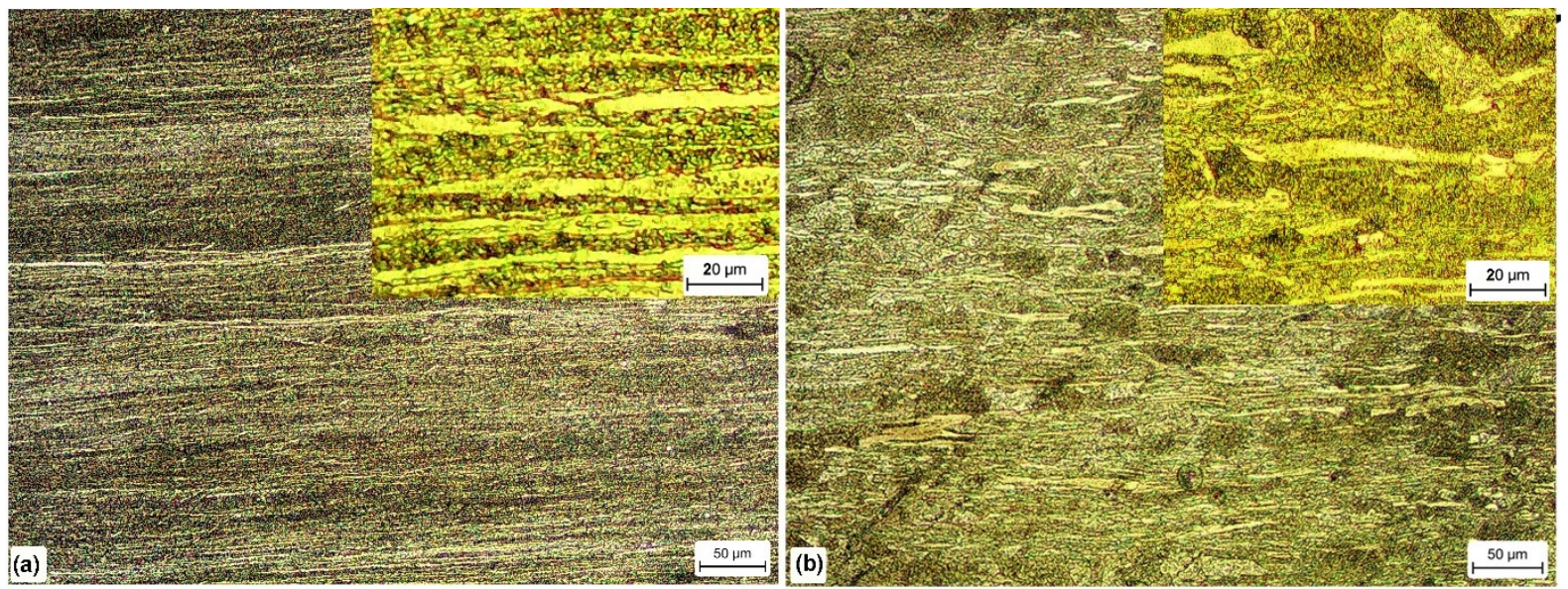

Fig. 3 Optical microstructure at different magnification for anode A (a) and anode B (b).

\section{Results and Discussion}

Some of the anode A surface area was completely lost and failed. Samples were taken close to the failed area and presented from both sides as shown in the Fig. 2a. The surface of the failed anode A is shown in Fig. 4. The surface of the sample showed two separate areas. The grey area is almost featureless and corrosion protected while the dark area looks heavily corroded. Fig. 5 represents the corrosion surface of the anode at low and high magnification together with the EDS analyses at different areas.
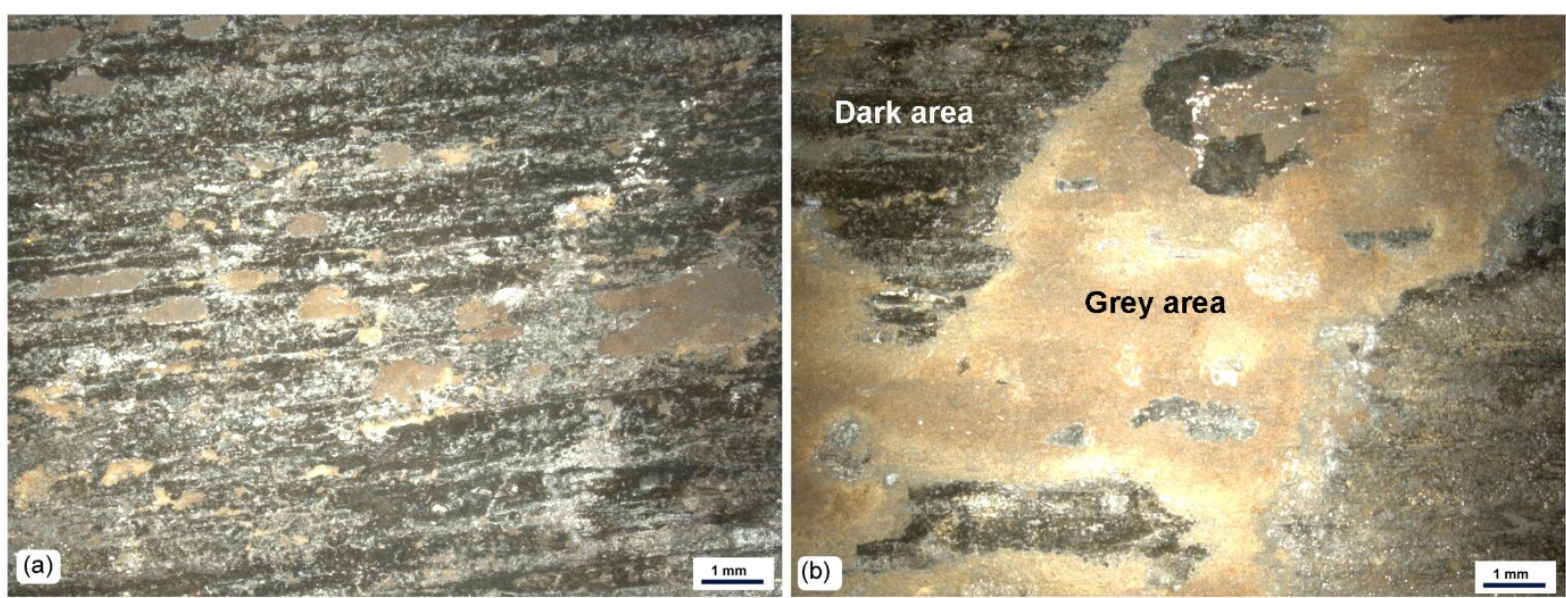

Fig. 4 Macrostructure of the anode A surface from two different areas 
It is clear from Fig. 5 that the surface consists of grey and black areas. Chemical analysis of the grey area suggested it is mainly lead(II) sulphate $\left(\mathrm{PbSO}_{4}\right)$ with traces of copper and calcium (spectrum 1). Meanwhile, the black area (spectrum 2) is mainly manganese dioxide with traces of other elements.
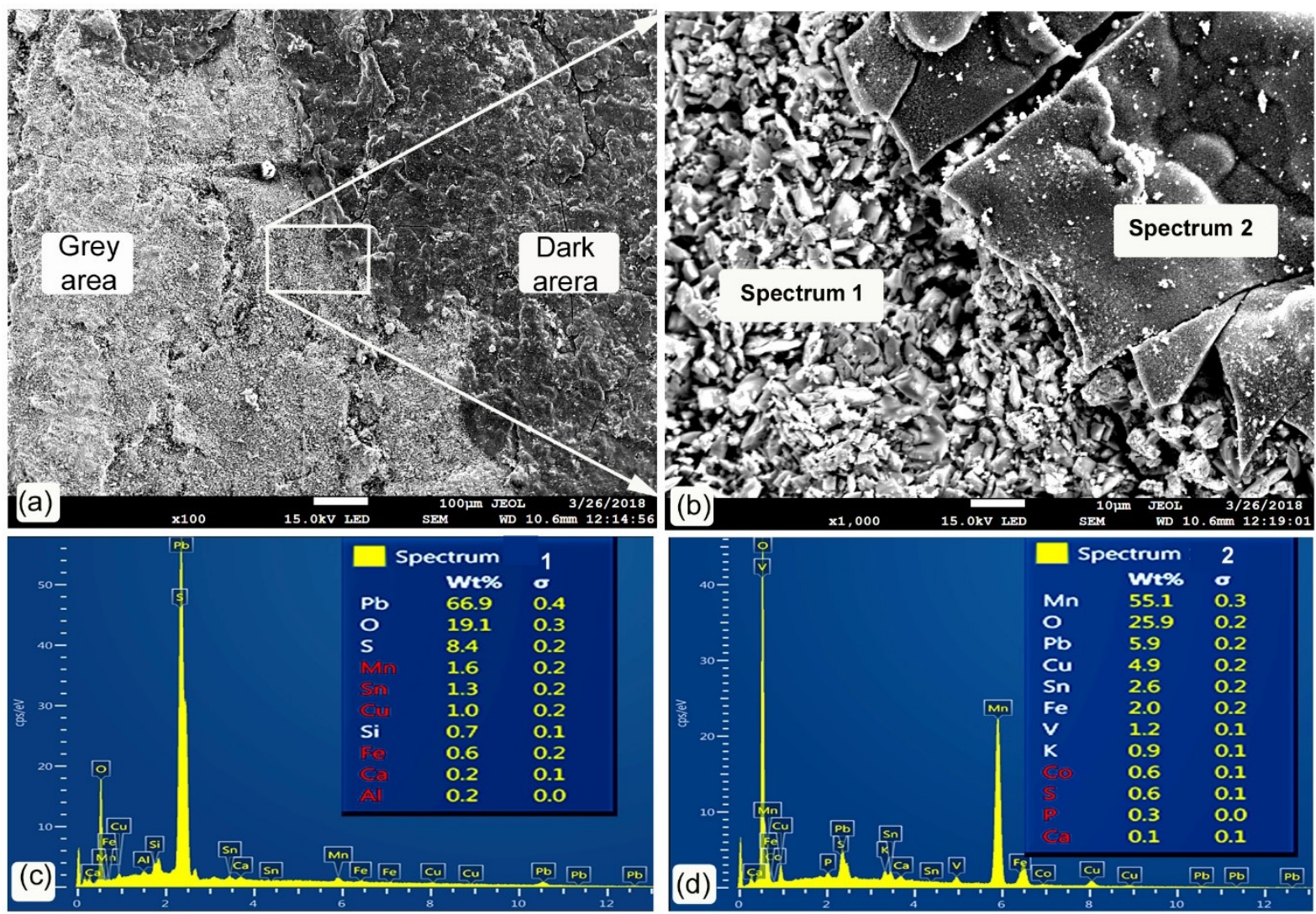

Fig. 5 SEM and EDS of the corroded anode A surface; (a) SEM at low magnification; (b) high magnification of rectangular area; (c) EDS analysis at spectrum 1; (d) EDS analysis at spectrum 2

The presence of manganese in the electrolyte causes many problems as indicated by some literature references $(7,12-14)$. Manganese is frequently found naturally in ores containing copper, zinc, nickel and cobalt. During the processing of these metallic ores, the separation of manganese from the other metals is not totally efficient, therefore, manganese eventually ends up as an impurity together with the other metals in leach solutions from which pure metals or compounds have to be produced.

It is worth noting that manganese intentionally added to the electrolyte in case of the elecrowinning of $\mathrm{Zn}$. In this process manganese is beneficial because of its effect to reduce both the anode dissociation and oxygen overpotential [15]. There is an evidence for the positive effect of $\mathrm{Mn}^{2+}$ ions if added together with Co but it is also favourable in case of using pure lead as anode in the electrowinning of $\mathrm{Zn} \mathrm{[16].}$ However, for $\mathrm{Cu}$ elecrowinning it is harmful to the process and should be discarded as much as possible. The corrosion rate significantly increases in the presence of manganese in the electrolyte [11].

The deterioration effect of manganese in the $\mathrm{Cu}$ electrowinning process is originating from its electrochemical activity to lead alloy anode. Manganese reaction is reported to initiate after the formation of lead dioxide. Manganese forms manganese dioxide which passivates the anode surface and impedes the oxygen evolution reaction [17]. The $\mathrm{MnO}_{2}$ formed on the anode has been characterised as a double layer. A thin well-adherent layer attached to the internal surface of the anode and a scaled fluffy thick layer to the electrolyte side. This thick layer is composed of Hexagonal $\varepsilon-\mathrm{MnO}_{2}$ as a non- 
adhering layer produced by oxidation on the $\mathrm{PbO}_{2}$ surface and a Tetragonal $\beta-\mathrm{MnO}_{2}$ which is produced by a chemical precipitation reaction at the electrode-electrolyte interface [18].

With the presence of sulphide in electrolytic solution, $\mathrm{MnO}_{2}$ layers start to build up and increase in thickness and possibly become less conductive and more inert within the oxygen evolution reaction. SEM and EDS in Fig. 5 shows formation of an inert $\mathrm{PbSO}_{4}$ layer between the $\mathrm{MnO}_{2}$ and the conductive $\mathrm{PbO}_{2}$ layers (spectrum 1). The $\mathrm{PbSO}_{4}$ is continuously converted to $\mathrm{PbO}_{2}$ at the anode but it will be in the form of fluffy, unattached scales. Therefore, $\mathrm{MnO}_{2}$ and $\mathrm{PbO}_{2}$ will continuously built up to form the thick easily to break scales. Hence, the black structure formed at the surface of anode (spectrum 2), as clearly shown in Fig. 5, is the easily loosing flakes of manganese dioxide. Fig 5b shows big cracks at this oxide which is a clear evidence of the brittleness and non-adherent characteristic of the oxide. This loosing of flakes can result in cathode contamination and may led to electrical shorts during which the protective oxides becomes overheated and broken into fragments of scales with the help of oxygen evolution. This process can continuously occur until the whole thickness of the anode is corroded and holes start to originate. This is the most probable assumption for the failure of the anode under a short time life.

The surface macrostructure of the failed anode B is shown in Fig. 2b. The received anode sample is heavily corroded with a large number of pits. More detailed surface macrostructures at different areas are shown in the 3D images in Fig. 6. The depths of pits are quite varied from less than $1 \mathrm{~mm}$ to almost $5 \mathrm{~mm}$ which indicates that the pits made several holes in the anode.
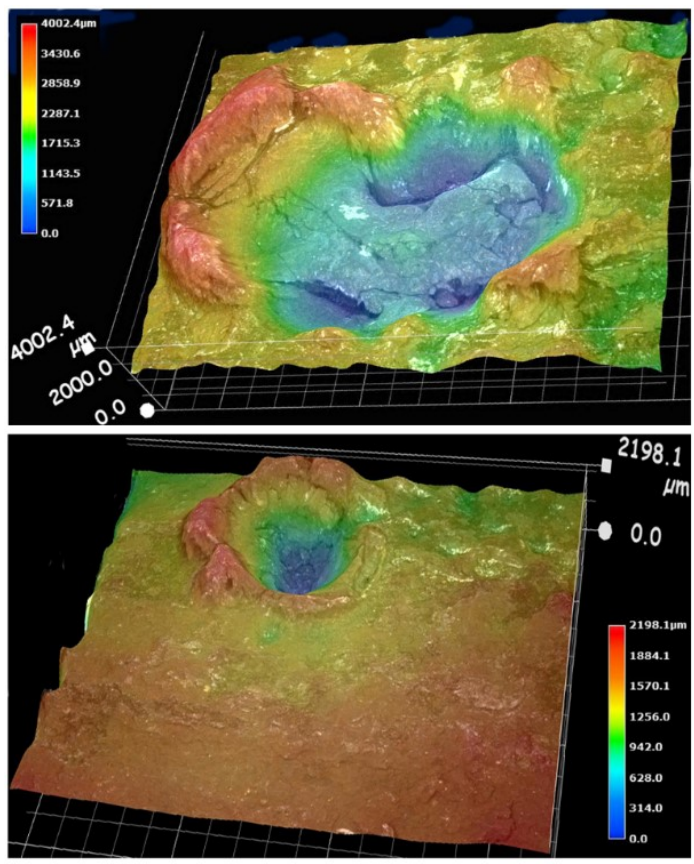

Fig. $63 \mathrm{D}$ photos for the pits formed at anode surface

The corroded surface inside the pit consisted of two main areas as shown in Fig. 7. Most of the area (Fig. 7a) contained the manganese dioxide as discussed in the previous section and the rest of areas contained fragments of lead(II) sulphate (Fig. 7b). Once again the manganese dioxide has a clearly cracked surface (spectrum 1) with corrosion products of lead oxides (spectrum 2). Traces of other elements are also present as corrosion products at the anode surface. Meanwhile, the surface of the anode outside the pits was mainly covered with manganese dioxide and white corrosion products stacked at some points to the surface as clearly shown in Fig. 8. 


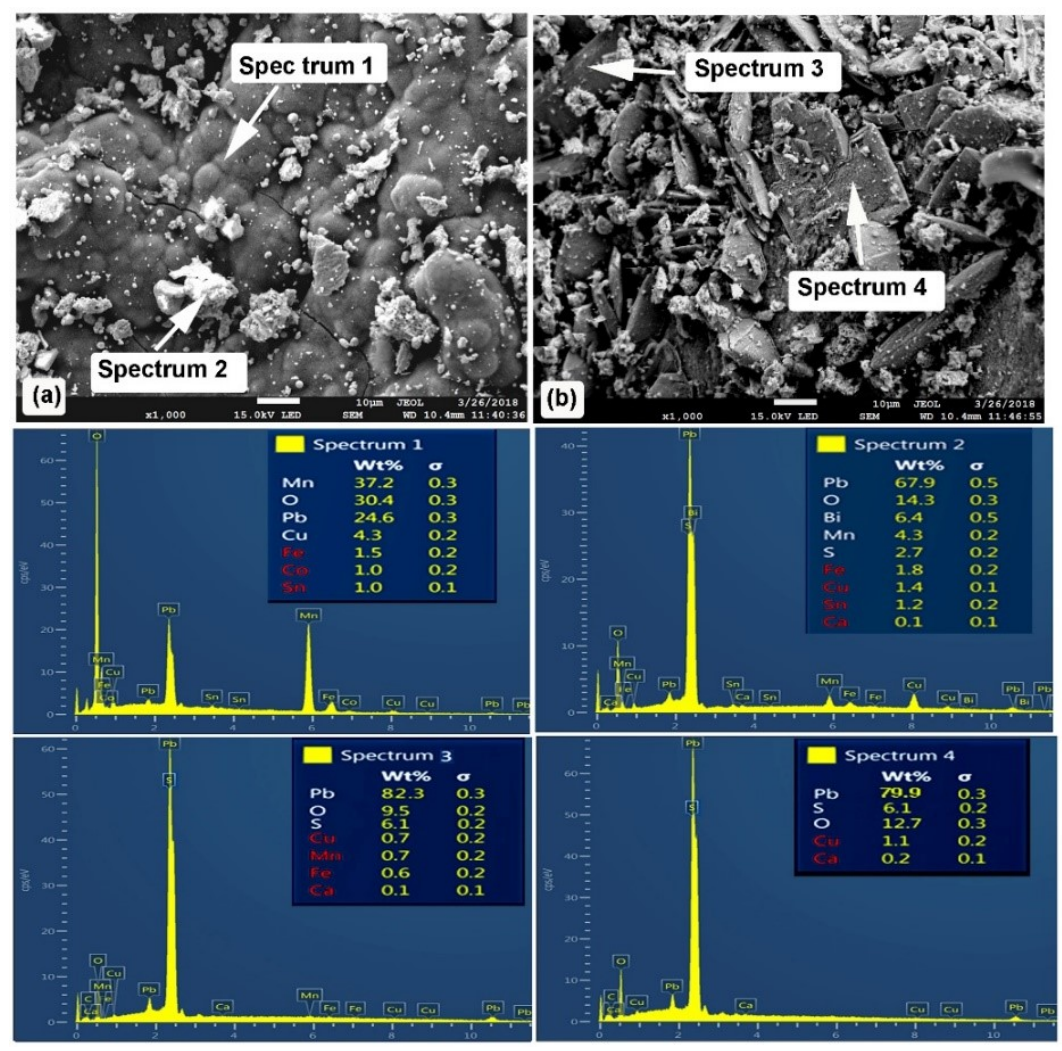

Fig. 7 SEM and EDS of the corroded anode B inside the pit

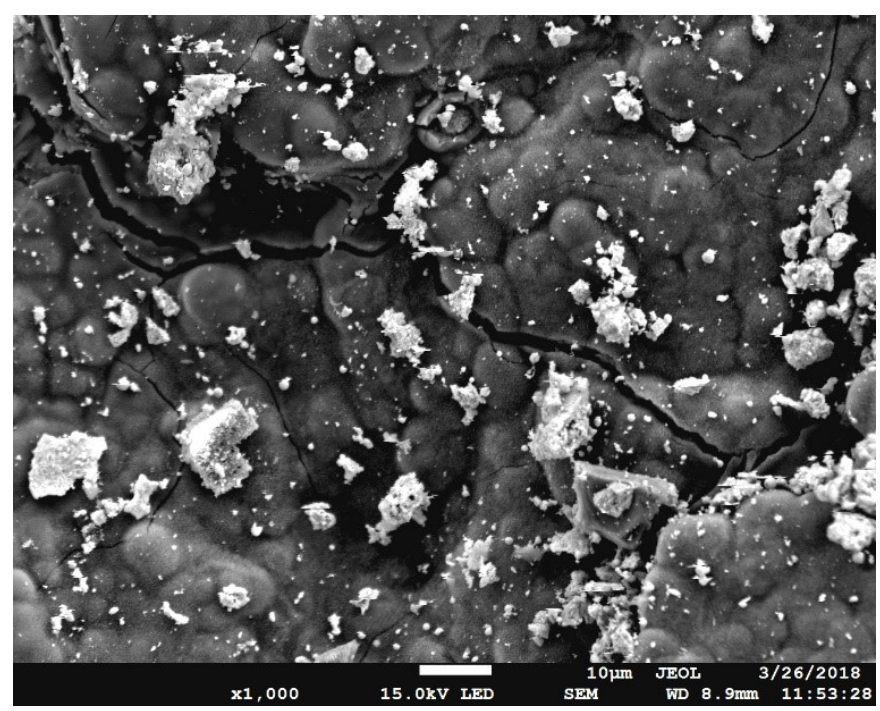

Fig. 8 SEM of the corroded anode surface outside the pit

Anode B is characterised by pitting corrosion in contrast to anode A, in spite of being in the same environment. The two anodes are from different manufacturers. Therefore, there should be a reason for this behaviour. Pitting corrosion is typically taking place while a metal in a passive state. Destroying the passive film at some areas causes the metal to lose its passivity and the pits rapidly initiate. During this process, the pit areas are considered local small anode sites relative to the big area of cathode around it. These local anodes areas could also be formed as a result of impurities, inhomogeneous on composition of metal, rough surface or other irregularities [19]. It is obvious from the microstructure shown in Fig. 3 that anode A is more homogeneous in respect to rolling lamination. Chemical composition as well was more homogeneous in anode A than anode B. EDS analyses of anode B showed more impurities such as $\mathrm{Si}$ and $\mathrm{Ni}$ in structure compared to anode $\mathrm{A}$. 
It is worth noting that the condition of the surface after rolling of anodes could play a vital role in governing the pitting corrosion. Unfortunately, no data is available related to surface condition of both anodes before employing them in the tank house. However, anode B was much more prone to pitting corrosion than anode A.

\section{Suggested Solutions}

There are a variety of techniques to control or solve the problem caused by manganese in the electrowinning process and these are described below. Choosing the most suitable and efficient method depends on a range of factors such as: severity of the problem, cost and economy of the process, level of technology understanding at the tank house, and availability of materials.

\section{Controlling manganese level in the electrolyte}

Minimising the level of manganese within the electrolyte is an obvious first step if this can be done. A target concentration of $40 \mathrm{mg} / \mathrm{L}$ has been suggested [7].

\section{Regular cleaning of the anodes}

It is not always possible to maintain manganese levels below $40 \mathrm{mg} / \mathrm{L}$. Where this is the case it has been recommended that the anodes are removed and cleaned at regular intervals [7]. This should minimise contamination of the copper cathodes and avoid excess power consumption during the electowinning process.

\section{Controlling electrolyte reduction potential (Eh)}

Another way to mitigate manganese problems is maintaining the electrolyte reduction potential (Eh) at around $400-450 \mathrm{mV}$ by addition of reductants. This helps to keep the manganese as $\mathrm{Mn}^{2+}$, rather than the higher valency states. This may be accomplished by addition of $\mathrm{SO}_{2}$ or addition of iron at around $1 \mathrm{~g} / \mathrm{L} \mathrm{Fe}^{2+}[12,20]$.

\section{Cobalt additions to the electrolyte}

Cobalt is beneficial if kept in the range of $100-200 \mathrm{mg} / \mathrm{L}$ in the electrolyte [7]. It is thought to limit the oxidation of manganese by promoting the evolution of oxygen at the anode. However more than $200 \mathrm{mg} / \mathrm{L}$ can reduce the cost efficiency of the process.

\section{Use of cation-exchange extractant}

Lastly, a cation-exchange extractant such as D2EHPA (di-2-ethylhexyl phosphoric acid) or hydroxyloximes can be used to selectively remove copper from aqueous solution. Impurities such as manganese can then be separated from the remaining solution. The copper loaded organic phase is then removed to produce a copper-rich sulfate solution for the electrowinning process [20-21].

\section{Conclusions}

1. The electrochemical performance of lead anodes relies on the protective ability of $\mathrm{PbO}_{2}$. A sufficiently thick layer of lead dioxide is essential to decrease the lead oxidation. The lead dioxide layer maintains the corrosion resistance of the anode provided it is dense, adherent and does not get dissolved.

2. High manganese is detrimental to the corrosion rate of lead anodes during normal tank house operation. It reacts with the protective lead oxide and produces loose flakes of unprotected manganese dioxide. This in turn can cause the failure of anodes in relatively short service times. 
3. Of the two anodes investigated, there were differences in homogeneity of chemical composition and lamination microstructures. The greater degree of microstructure inhomogeneity and impurity levels in one of the anodes is thought to have led to a severe pitting attack.

4. Many methods are available to overcome the manganese problem including preventing manganese from getting into the electrolyte by regularly cleaning the anodes, preventing $\mathrm{Mn}^{2+}$ oxidation to higher valency, addition of cobalt, and recovery of copper separately from the solution by using cation-exchange extractants.

\section{Acknowledgement}

The ASTUTE 2020 (Advanced Sustainable Manufacturing Technologies) operation, supporting manufacturing companies across Wales, has been part-funded by the European Regional Development Fund through the Welsh Government and the participating Higher Education Institutions. The Authors would like also to express their great appreciation to the Advanced Imagining of Materials (AIM) department at Swansea University for using their facilities and equipment.

\section{References}

[1] M. Moats, M. Free, A bright Future for Copper Electrowinning, JOM. 59(10), 34-36(2007).

[2] R.D. Prengaman, A. Siegmund, Improved copper electrowinning operations using wrought $\mathrm{Pb}-\mathrm{Ca}-$ Sn anodes. 4th International Conference COPPER 99-COBRE 99. 561-573(1999).

[3] M. Tunnicliffe, F. Mohammadi, A. Alfantazi, Polarization Behaviour of Lead Silver Anodes in Zinc Electrowinning Electrolytes. J. Electrochem. Soc. 159 (4), C170-C180 (2012).

[4] A. Felder, R.D. Prengaman, Lead alloys for permanent Anodes in the Nonferrous metals industry. JOM. 58(10), 28-31(2006).

[5] I. Ivanov, Y. Stefanov, Z. Noncheva, M. Petrova, Ts. Dobrev, L. Mirkova, R. Vermeersch, J.P. Demaerel, Insoluble Anodes Used in Hydrometallurgy: Part I. Corrosion Resistance of Lead and Lead Alloy Anodes, Hydrometall. 57:109-124(2000).

[6] I. Ivanov, Y. Stefanov, Z. Noncheva, M. Petrova, Ts. Dobrev, L. Mirkova, R. Vermeersch, J.P. Demaerel, Insoluble Anodes Used in Hydrometallurgy: Part II. Anodic Behaviour of Lead and LeadAlloy Anodes, Hydrometall. 57:125-139(2000).

[7] A. Mirza, M. Burr, T. Ellis, D. Evans, D. Kakengela, L. Webb, J. Gagnon, F. Leclercq, A. Johnston, Corrosion of Lead Anodes in Base Metals Electrowinning, J. South Afr. Inst. Min. Metall., 116, 533538(2016).

[8] R.D. Prengaman, H.B. Mcdonald, Stable Lead Dioxide Anode and Method for Production. US patent 4, 236,978. RSR Corporation, Dallas, TX(1980).

[9] O. Hyvarinen, The Effect of Silver and Cobalt on the Oxygen Evolution at Lead Anodes. Laboratory of Process Metallurgy, Helsinki University of Technology, Otaniemi, Finland (1972).

[10] C.P. Camurri, M.J. López, A.N. Pagliero, F.G. Vergara, Deformations in Lead-Calcium-Tin Anodes for Copper Electrowinning, Mater. Charact. 47, 105-109(2001).

[11] M. Clancy, C.J. Bettles, A. Stuart, N. Birbilis, The Influence of Alloying Elements on the Electrochemistry of lead Anodes for Electrowinning of Metals, A review, Hydrometall., 131-132: 144157(2013). 
[12] G. Miller, The Problems of Manganese and its Effects on Copper SX-EW operations, Copper 95 Cobre 95, Electrorefining and Hydrometallurgy of Copper, vol. 3. Cooper, W.C., Dreisinger, D.B., Dutrizac, J.E., Hein, H., and Ugarte, G. (eds.). Canadian Institute of Mining, Metallurgy and Petroleum, Montreal. 649-663(1995).

[13] C. Hughes, K. Barnard, C.Y. Cheng, K. Larcombe, The Role of Contaminants in Phase Separation During Copper Solvent Extraction, Proceedings of the ALTA Copper Hydrometallurgy Forum, Brisbane, Australia (1998).

[14] L. Cifuentes, E. Aatete, G. Crisostomo, J. Sinpson, G. Cifuentes, M. Pilleux, Corrosion and Protection of Lead Anodes in Acidic Copper Sulphate solutions. Corros. Eng. Sci. and Techn., 40: 321-327(2005).

[15] C. Cachet, C. Le Pape-Rérolle, R. Wiart, Influence of $\mathrm{Co}^{2+}$ and $\mathrm{Mn}^{2+}$ ions on the kinetics of lead anodes for zinc electrowinning, J. Appl. Electrochem., 29 (7), 813-820(1999).

[16] W. Zhang, C. Y. Cheng, Manganese metallurgy review. Part III: Manganese control in zinc and copper electrolytes, Hydrometall. 89 178-188(2007)

[17] P. Yu, T. J. O'Keefe, Evaluation of Lead Anode Reactions in Acid Sulfate Electrolytes II. Manganese Reactions, J. Electrochem. Soc. 149 (5) A558-A569 (2002)

[18] V. Tjandrawan, The role of Manganese in the electrowinning of copper and zinc, Doctoral Dissertation, Murdoch University, Western Australia, (2010).

[19] Z. Ahmad, Principles of Corrosion Engineering and Corrosion Control, Butterworth Heinemann (2006).

[20] W. Zhang, C.Y. Cheng, Manganese Metallurgy Review. Part III: Manganese Control in Zinc and Copper Electrolytes, Hydrometall. 89: 178-188(2007).

[21] N.V.Thakur, S.L. Mishra, Separation of $\mathrm{Co}$, Ni and $\mathrm{Cu}$ by solvent extraction using di-(2ethylhexyl) phosphonic acid, PC 88A, Hydrometall. 48: 277-289(1998). 
Lead

$\alpha-\mathrm{PbO}_{2}$

$\mathrm{B}-\mathrm{PbO}_{2}$ 

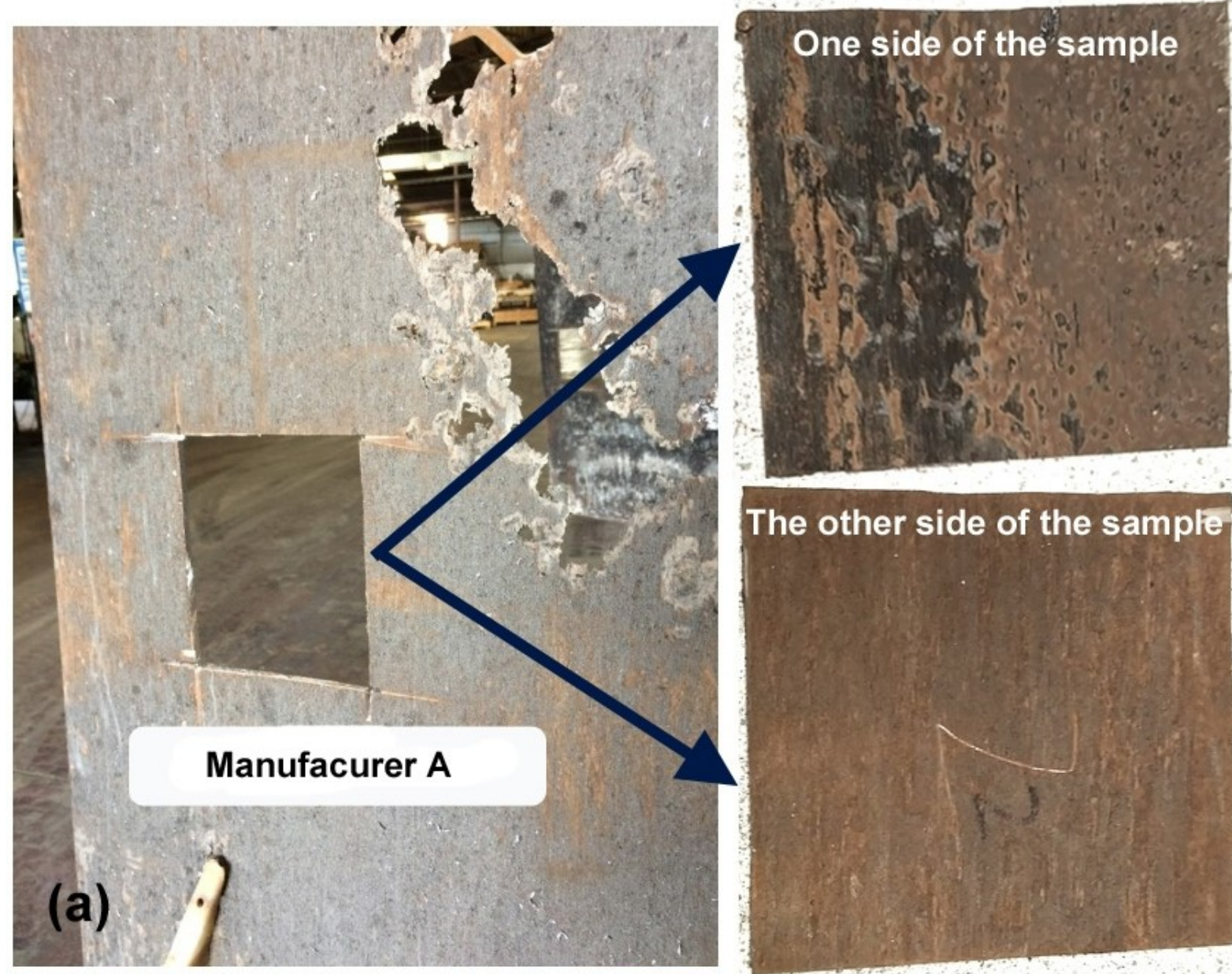

The other side of the sample
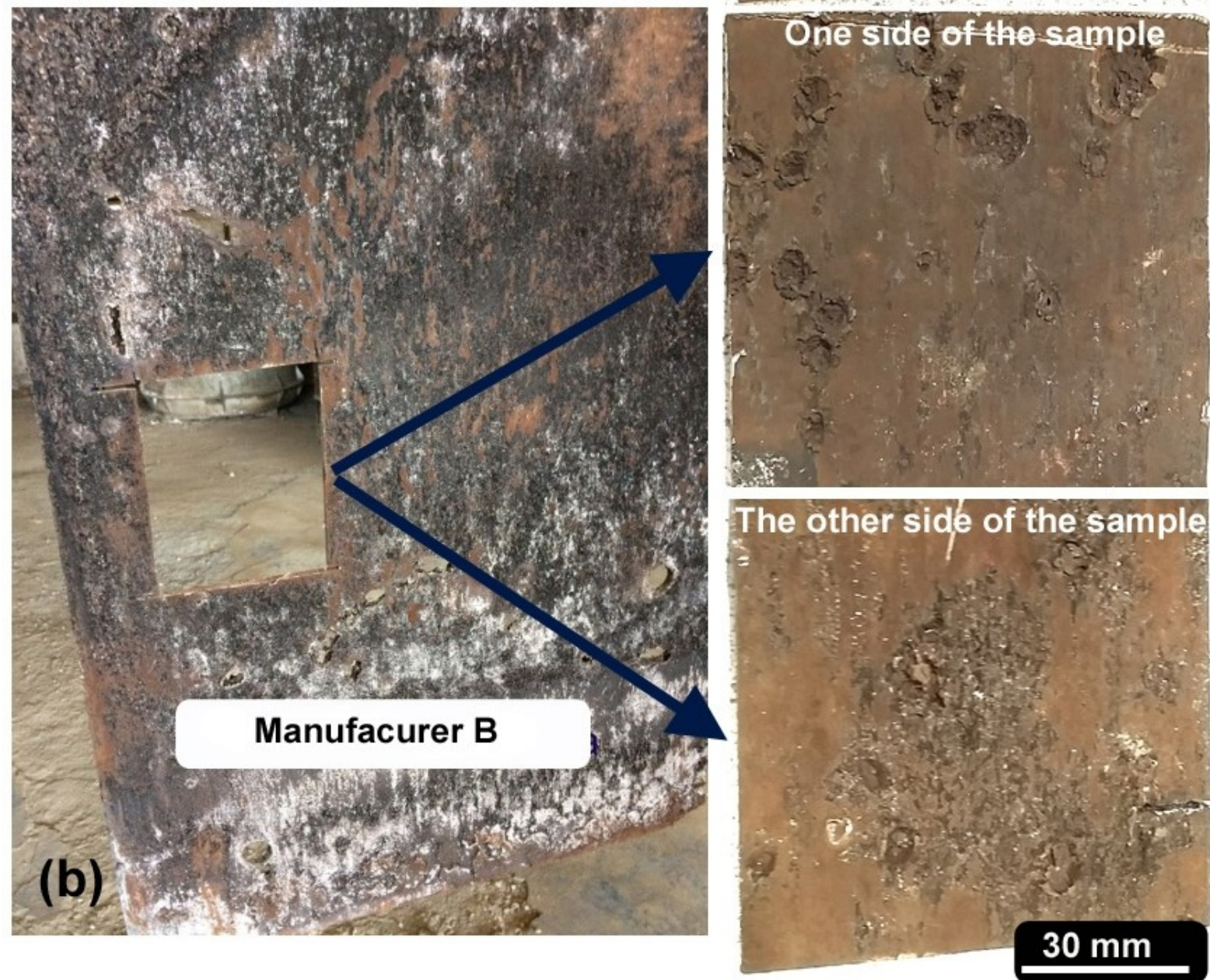

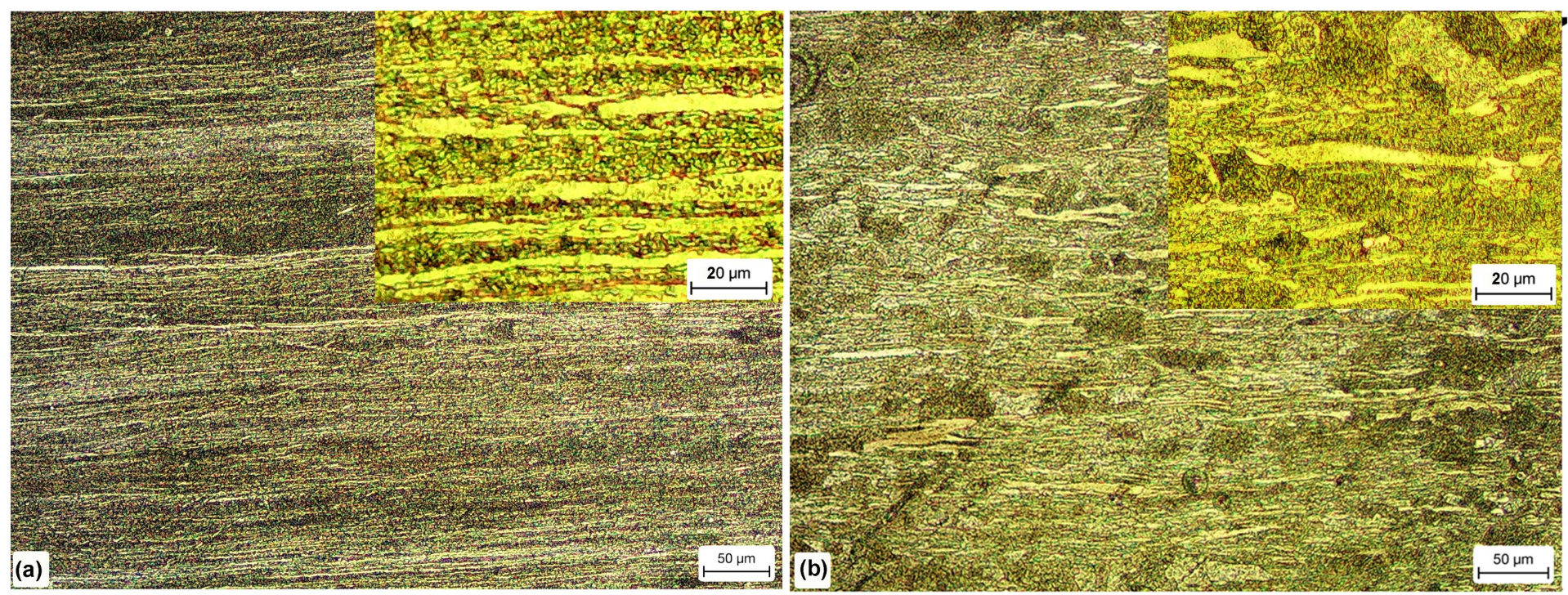

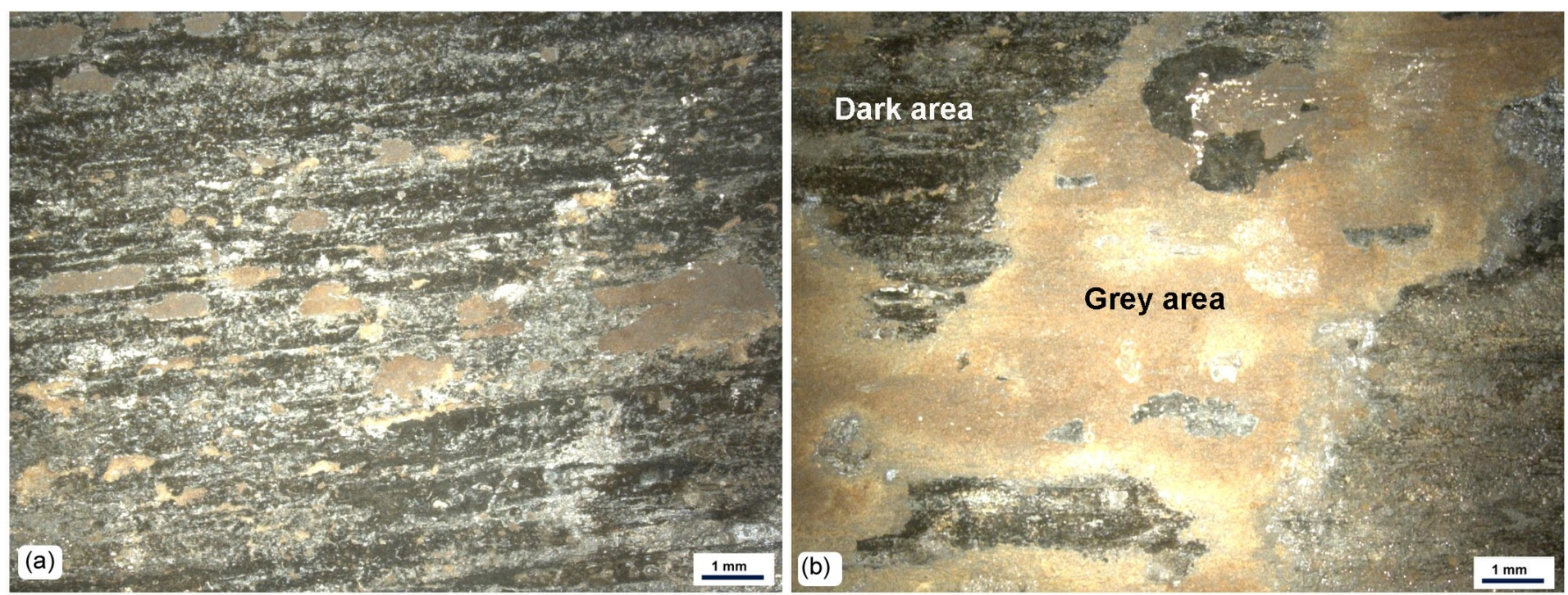

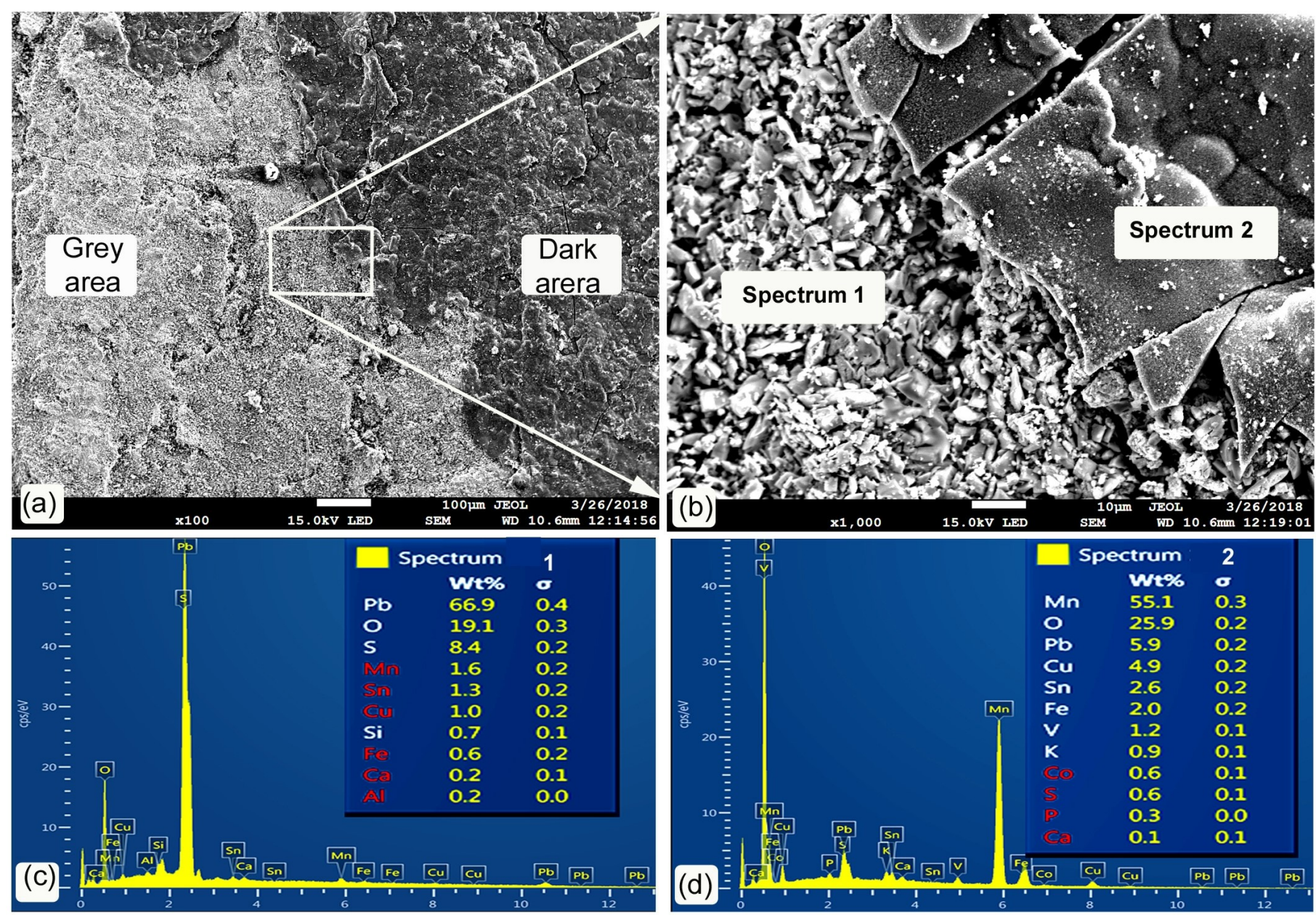

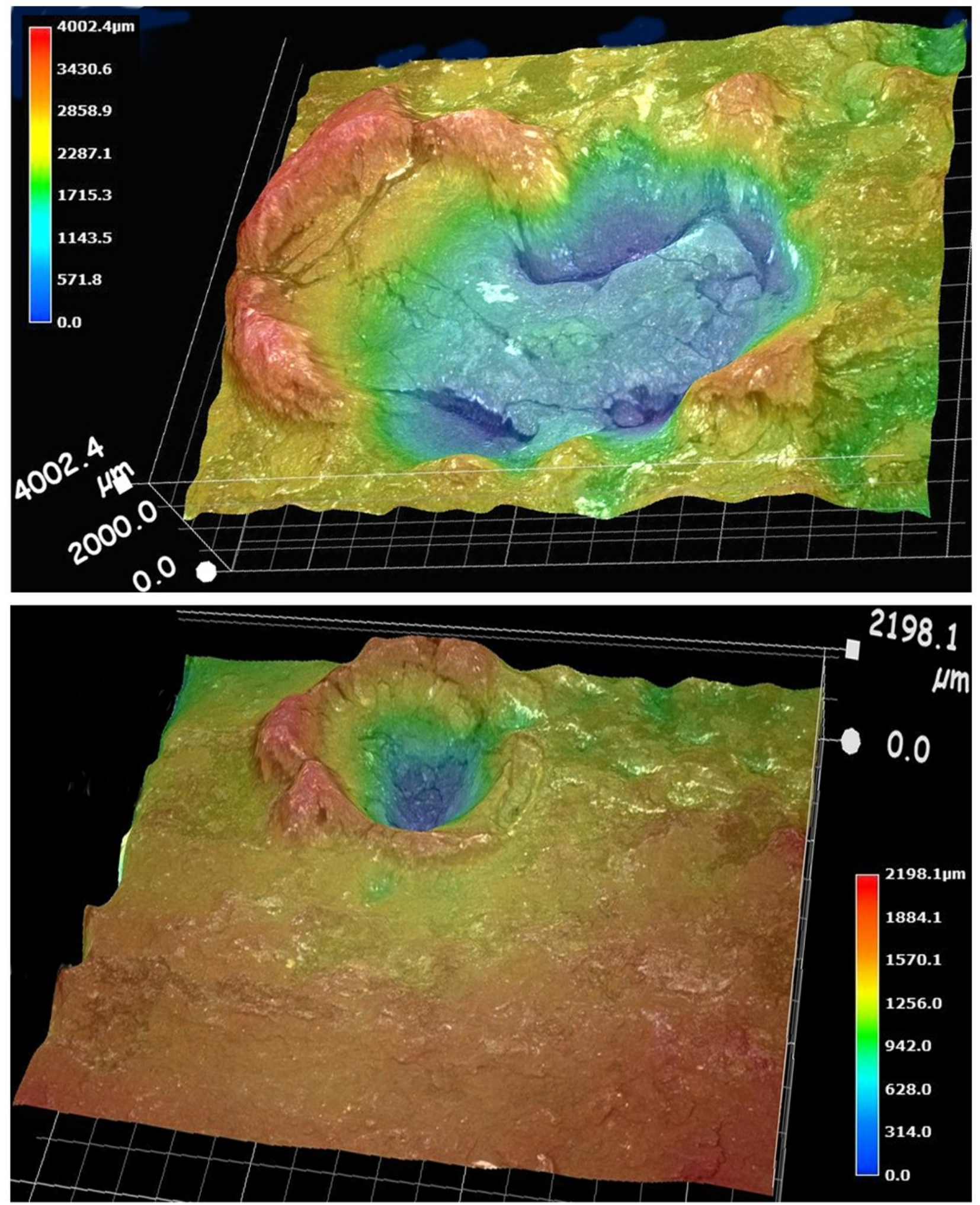


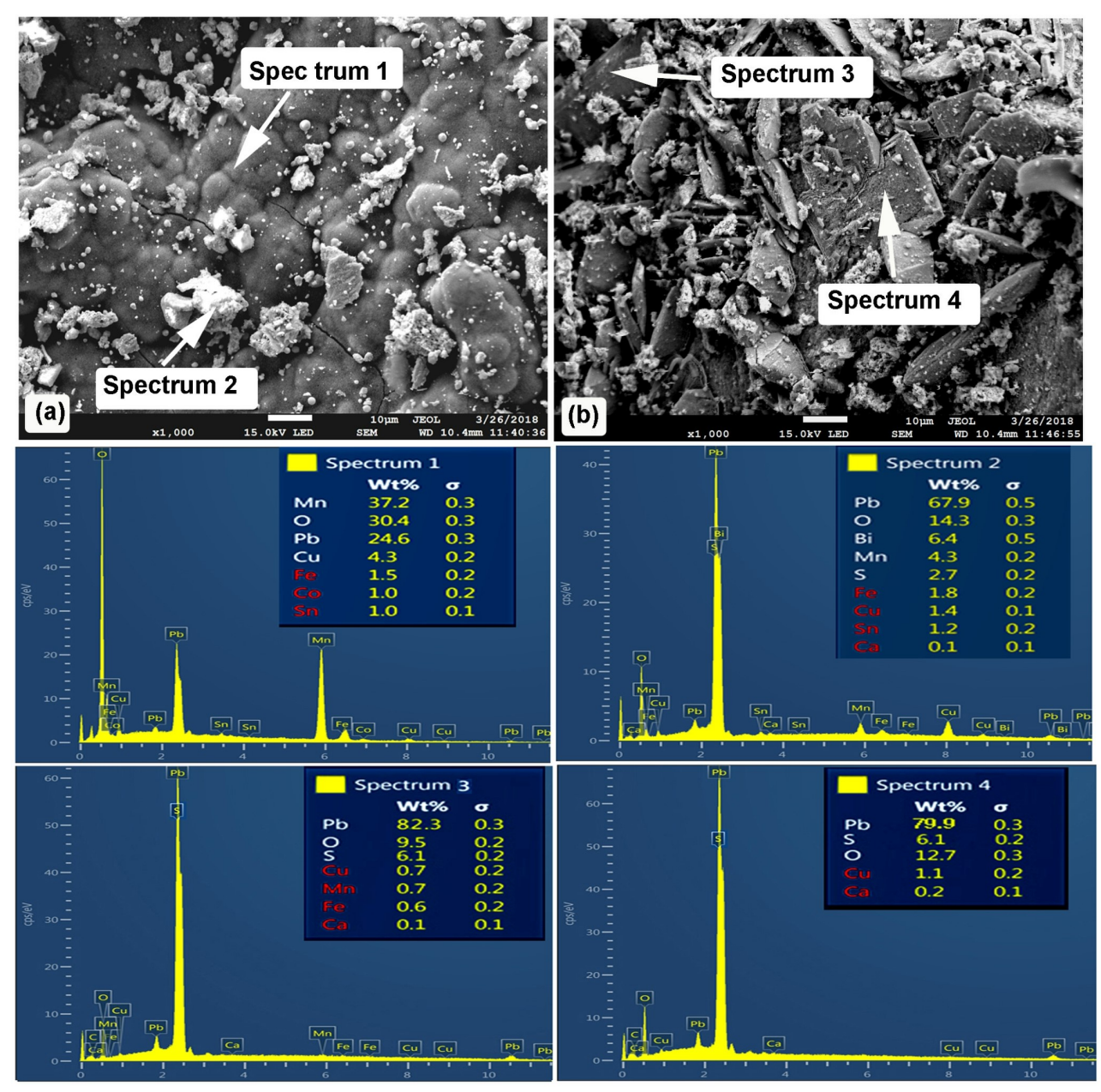




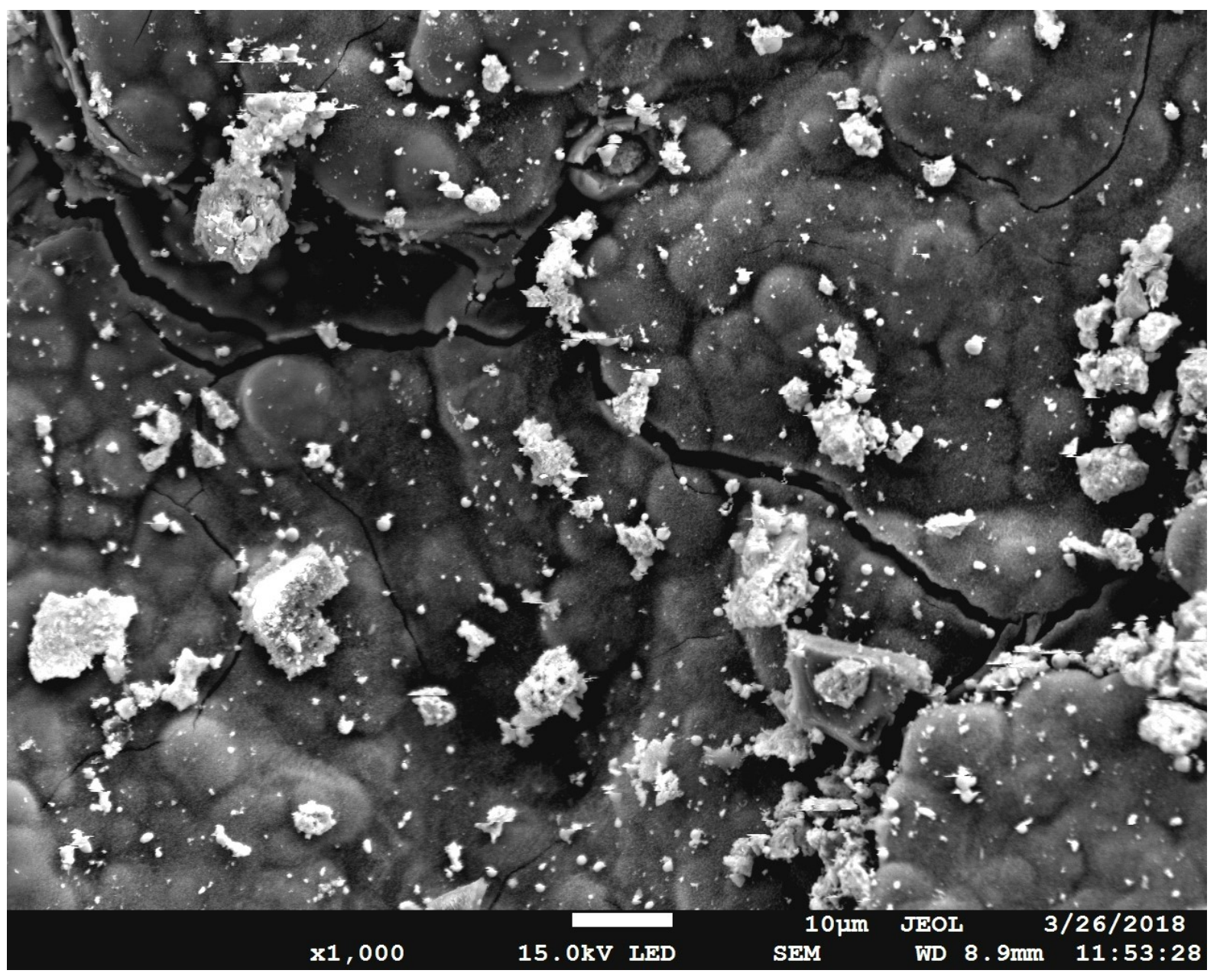




\section{AUTHOR DECLARATION}

We wish to confirm that there are no known conflicts of interest associated with this publication and there has been no significant financial support for this work that could have influenced its outcome.

We confirm that the manuscript has been read and approved by all named authors and that there are no other persons who satisfied the criteria for authorship but are not listed. We further confirm that the order of authors listed in the manuscript has been approved by all of us.

We confirm that we have given due consideration to the protection of intellectual property associated with this work and that there are no impediments to publication, including the timing of publication, with respect to intellectual property. In so doing we confirm that we have followed the regulations of our institutions concerning intellectual property.

We understand that the Corresponding Author is the sole contact for the Editorial process (including Editorial Manager and direct communications with the office). He is responsible for communicating with the other authors about progress, submissions of revisions and final approval of proofs. We confirm that we have provided a current, correct email address which is accessible by the Corresponding Author and which has been configured to accept email from (ahmed.elrefaey@swansea.ac.uk)

Signed by:

A. Elrefaey

$$
\text { Ahut Elreforey 15/10/2, o }
$$

On behave of all authors 